\title{
Thyroid Hormone Levels in Chronic Schizophrenic Patients: Association with Psychopathology
}

\author{
S Telo $^{1}$, S Bilgic ${ }^{2}$, N Karabulut ${ }^{3}$
}

\begin{abstract}
Objectives: Thyroid disorders are highly prevalent in patients with schizophrenia. Changes in the levels of thyroid hormones cause the occurrence of psychiatric disorders and affect the response to treatment. The aim of this study was to investigate the changes in thyroid hormone levels in patients with chronic schizophrenia, and to demonstrate any association between psychiatric symptoms and hormones.

Methods: Sixty-three patients with schizophrenia and 53 controls were included in this study. The serum levels of free triiodothyronine (FT3), free thyroxine (FT4) and thyroid-stimulating hormone (TSH) in patients and controls were tested by using the chemiluminescence immunoassay. Symptoms were assessed via the Positive and Negative Syndrome Scale (PANSS). Results: The level of FT4 in the schizophrenia group was statistically significantly lower than the control group $(p=0.045)$. There was no significant difference between the clinical subtypes of schizophrenia and thyroid hormone levels. There was a mild negative correlation between PANSS negative subscale scores and levels of TSH ( $p=0.023)$.

Conclusion: These findings suggest that the subclinical hypothyroidism observed in the chronic schizophrenic patients may be associated with the treatment of neuroleptics. The possible alterations of thyroid hormones should be considered in chronic schizophrenic patients for treatment with neuroleptics.
\end{abstract}

Keywords: Neuroleptic drugs, schizophrenia, thyroid hormones

\section{Niveles de hormona tiroidea en pacientes esquizofrénicos crónicos: asociación con la psicopatología \\ S Telo $^{1}$, S Bilgic ${ }^{2}$, N Karabulut ${ }^{3}$}

\begin{abstract}
RESUMEN
Objetivos: Los trastornos de la tiroides son altamente prevalentes en los pacientes con esquizofrenia. Los cambios en los niveles de hormonas tiroideas provocan la aparición de trastornos psiquiátricos y afectan la respuesta al tratamiento. El objetivo de este estudio fue investigar los cambios en los niveles de hormona tiroidea en pacientes con esquizofrenia crónica y demostrar cualquier asociación entre los síntomas psiquiátricos y las hormonas.

Métodos: Sesenta y tres pacientes con esquizofrenia y 53 controles se incluyeron en este estudio. Los niveles séricos de triyodotironina libre (FT3), tiroxina libre (FT4) y tirotropina u hormona estimulante de la tiroides (TSH) en pacientes y controles, se analizaron utilizando el immunoensayo de quimioluminescencia. Los sintomas fueron evaluados mediante la Escala de Síndromes Positivos y Negativos (ESPN).

Resultados: El nivel de FT4 en el grupo de esquizofrenia fue estadísticamente significativamente más bajo que el del grupo de control ( $p=0.045)$. No hubo diferencias significativas entre los subtipos clínicos de esquizofrenia y los niveles de hormona tiroidea. Hubo una leve correlación negativa entre las puntuaciones de la subescala negativa ESPN y los niveles de TSH $(p=0.023)$.

Conclusión: Estos resultados sugieren que el hipotiroidismo subclínico en los pacientes con es-
\end{abstract}

From: ${ }^{1}$ Medical Biochemistry Laboratory, Mental Health Hospital, 23200 Elazig, Turkey, ${ }^{2}$ Department of Psychiatry, Geyve State Hospital, Sakarya, Turkey and ${ }^{3}$ Medical Microbiology Laboratory, Mental Health Hospital, 23200 Elazig, Turkey.
Correspondence: Dr S Telo, Medical Biochemistry Laboratory, Mental Health Hospital, 23200 Elazig, Turkey. Fax: +90 424 2127831; e-mail: drseldatelo@hotmail.com 
quizofrenia crónica puede estar asociado con el tratamiento con neurolépticos. Las posibles alteraciones de las hormonas tiroideas se deben considerar en pacientes esquizofrénicos crónicos bajo tratamiento con neurolépticos.

Palabras claves: fármacos neurolépticos, esquizofrenia, hormonas tiroideas

West Indian Med J 2016; 65 (2): 313

\section{INTRODUCTION}

Schizophrenia is a severe neurodegenerative brain disorder characterized by hallucinations, delusions, disorganized thoughts and cognitive abilities. Risk factors for schizophrenia also include maternal exposure to stress, infection or immune activation, nutritional deficiencies, obstetric complications and use of cannabis (1). Thyroid hormones (TH) are necessary for the development and maturation of the brain and are also essential for the functioning of the mature brain $(2,3)$.

Many different factors influence the effects of TH in the brain: availability of iodine, thyroid disorders and dysfunction and mutations of thyroid axis-related proteins (2). High prevalence of thyroid dysfunction in schizophrenic patients has been shown (4). Changes in the levels of TH cause the occurrence of psychiatric disorders and affect the response to treatment $(2,3)$. Thyroid hormones are important for modulation of dopaminergic, serotonergic, glutamatergic, and GABAergic networks. It has been shown that $\mathrm{TH}$ regulate the levels of dopamine receptors and the activity of tyrosine hydroxylase (3). Thyroid hormone receptors are localized to limbic structures acting on mood regulation (4).

Case reports have shown that individuals with hyperthyroidism may manifest psychosis. Moreover, hypothyroid individuals can have depressive symptoms similar to the negative symptoms seen in schizophrenic patients (3). Thyroid hormones have been extensively investigated in major depressive and bipolar disorders $(4,5)$. But there are limited data on alteration of the $\mathrm{TH}$ in patients with schizophrenia (4).

The aim of this study was to investigate the changes of $\mathrm{TH}$ levels in schizophrenic patients, and whether there is a correlation between Positive and Negative Syndrome Scale (PANNS) and TH.

\section{SUBJECTS AND METHODS}

This study was approved by the Firat University Medicine Ethics Committee (2014/03/07). This study was conducted in the Elazıg Mental Health Hospital. Sixty-three inpatients (31 males, 32 females) who were diagnosed with schizophrenia by Diagnostic and Statistical Manual of Mental Disorders, Fourth Edition, Text Revision (DSM-IV-TR) were included in the study. All of the patients were using a variety of neuroleptic drugs. These drugs included chlorpromazine, clozapine, risperidone, haloperidol, quetiapine, olanzapine and amisulpride.

The patients using lithium, carbamazepine and phenytoin were excluded from the study. Positive and Negative Syndrome Scale is a medical scale used for measuring symptoms of patients with schizophrenia. The results of TH and medication information were collected from patients' charts.

Fifty-three patients (26 males and 27 females) who were not diagnosed with any psychiatric disorder comprised the control group. None of the controls was taking any medication or had a history of thyroid disorder.

\section{Biochemical analysis}

The serum levels of free triiodothyronine (FT3), free thyroxine (FT4) and thyroid-stimulating hormone (TSH) in patients and controls were performed by using the immunoassay analyser ADVIA Centaur XP (Siemens Diagnostics, Tarrytown, NY, USA) in the clinical laboratory of the hospital.

\section{Statistical analyses}

Statistical analyses were performed using SSPS 21 (SPSS Inc, Chicago, IL, USA). The Student's $t$-test was used to compare parameters among the groups. The Chi-squared test was used for categorical comparisons of nominal values in different groups. The one-way analysis of variance (ANOVA) or the Kruskal-Wallis tests, where appropriate, was used to compare parameters among the groups of schizophrenia subtypes. The correlation coefficients and their significance were calculated using the Spearman test; $p \leq 0.05$ was considered statistically significant.

\section{RESULTS}

Sixty-three patients with schizophrenia were included in the study: 18 with paranoid, eight with disorganized, five with undifferentiated, 22 with residual, nine with simple schizophrenia and one individual with catatonic type. The mean age of the patients was $44.67 \pm 10.38$ (range $18-69$ years) and $41.37 \pm 8.19$ (range 27-58) years in controls. The mean of the disease duration in schizophrenic patients was 15.75 \pm 10.04 (range 3-40 years). No significant differences were seen between patients and controls in terms of age and gender. Free thyroxine was significantly lower in patients than healthy controls. However, no difference in FT3 and TSH levels were detected among groups (Table 1).

When FT3, FT4 and TSH levels in subgroups of schizophrenia were evaluated, no statistically significant differences among five schizophrenia subtypes were seen (Table 2). There was a significant negative correlation between PANSS negative scale and levels of TSH. No correlation was determined between levels of FT3, FT4 and symptom severity of patients with schizophrenia (Table 3). 
Table 1: Clinical and demographic characteristics of schizophrenic patients and healthy controls

\begin{tabular}{lccc}
\hline & Patients $(\mathbf{n}=\mathbf{6 3})$ & Controls $(\mathbf{n}=\mathbf{5 3})$ & $\boldsymbol{p}$ \\
\hline Age (year) & $44.67 \pm 10.38$ & $41.64 \pm 8.02$ & 0.086 \\
Gender (F/M) & $32 / 31$ & $27 / 26$ & 0.987 \\
Duration of & & & \\
illness (years) & $15.75 \pm 10.04$ & & \\
FT3 (pg/mL) & $3.12 \pm 0.47$ & $3.14 \pm 0.54$ & 0.806 \\
FT4 (ng/dL) & $1.04 \pm 0.18$ & $1.14 \pm 0.36$ & 0.045 \\
TSH (mU/l) & $2.15 \pm 1.53$ & $1.86 \pm 2.26$ & 0.164 \\
PANSS-N & $30.31 \pm 8.49$ & & \\
PANSS-P & $17.02 \pm 10.51$ & & \\
PANSS-GP & $35.53 \pm 14.62$ & & \\
PANSS & $82.05 \pm 23.65$ & & \\
\hline
\end{tabular}

FT3: free triiodothyronine; FT4: free thyroxine; TSH: thyroid-stimulating hormone; PANSS: Positive and Negative Syndrome Scale; N: negative scale; $p$ : positive scale; GP: general psychopathology scale

Table 2: Comparison of the levels of thyroid hormones among the groups of schizophrenia subtypes

\begin{tabular}{lcccccc}
\hline & $\begin{array}{c}\text { Paranoid } \\
(\mathbf{n}=\mathbf{1 8})\end{array}$ & $\begin{array}{c}\text { Disorganized } \\
(\mathbf{n}=\mathbf{8})\end{array}$ & $\begin{array}{c}\text { Undifferentiated } \\
(\mathbf{n}=\mathbf{5})\end{array}$ & $\begin{array}{c}\text { Residual } \\
(\mathbf{n = 2 2})\end{array}$ & $\begin{array}{c}\text { Simple schizophrenia } \\
(\mathbf{n}=\mathbf{9})\end{array}$ & $\boldsymbol{p}$ \\
\hline FT3 & $3.18 \pm 0.54$ & $2.99 \pm 0.45$ & $2.80 \pm 0.54$ & $3.13 \pm 0.43$ & $3.22 \pm 0.41$ & 0.354 \\
FT4 & $1.02 \pm 0.22$ & $0.99 \pm 0.12$ & $0.99 \pm 0.13$ & $1.09 \pm 0.16$ & $1.10 \pm 0.20$ & 0.558 \\
TSH & $2.52 \pm 1.56$ & $1.99 \pm 1.05$ & $1.57 \pm 2.14$ & $2.19 \pm 1.65$ & $1.51 \pm 0.83$ & 0.162 \\
\hline
\end{tabular}

FT3: free triiodothyronine; FT4: free thyroxine; TSH: thyroid-stimulating hormone

Table 3: Correlations between thyroid hormones and symptom severity of patients with schizophrenia

\begin{tabular}{lcccc}
\hline & $\begin{array}{c}\text { PANSS-N } \\
\mathbf{r}(\boldsymbol{p})\end{array}$ & $\begin{array}{c}\text { PANSS-P } \\
\mathbf{r}(\boldsymbol{p})\end{array}$ & $\begin{array}{c}\text { PANSS-GP } \\
\mathbf{r}(\boldsymbol{p})\end{array}$ & $\begin{array}{c}\text { PANSS } \\
\mathbf{r}(\boldsymbol{p})\end{array}$ \\
\hline FT3 & $-0.125(0.346)$ & $-0.126(0.337)$ & $-0.224(0.088)$ & $-0.190(0.165)$ \\
FT4 & $0.014(0.915)$ & $-0.239(0.069)$ & $-0.078(0.562)$ & $-0.163(0.239)$ \\
TSH & $-0.307(0.023)^{*}$ & $0.209(0.122)$ & $0.105(0.444)$ & $0.087(0.543)$
\end{tabular}

$* p<0.05$

FT3: free triiodothyronine; FT4: free thyroxine; TSH: thyroid-stimulating hormone; PANSS: Positive and Negative Syndrome Scale; N: negative scale; $P$ : positive scale; GP: general psychopathology scale

\section{DISCUSSION}

In the present study, FT4 levels were significantly decreased in patients with schizophrenia compared with control, but no significant difference in TSH levels was determined among the groups. We postulate that the subclinical hypothyroidism observed in these patients may be associated with treatment with neuroleptics. Dysfunction of the thyroid is common in schizophrenic patients under antipsychotic treatment (6). Mainly, neuroleptic medication may affect thyroid hormone metabolism (7). Animal studies have shown that treatment with antipsychotics such as clozapine and haloperidol was related to changes in expression of nuclear receptors and genes involved in thyroid hormone function (4). Many neuroleptic medications block dopaminergic transmission and result in elevated levels of TSH (3).

Several previous studies have reported that FT4 levels increased in the schizophrenic patients during the first hospitalization $(1,8)$. Thyroid hormones appear to act as neuromodulators (9). Elevated T4 levels were interpreted as 'stress-induced' in schizophrenic patients who were admitted to hospital for the first time by the authors $(9,10)$. The pituitary gland may be the most affected region of the brain, especially in the hypothalamic-pituitary- adrenal (HPA) axis by the hormonal stress response. Hyperactivity of HPA in schizophrenia has been defined and it has been thought to be a response to stress-induced hormonal dysregulation (11). Baumgartner et al (7) reported elevated T4 levels with normal T3, rT3 and TSH levels in patients with schizophrenia. Rises in T4 levels have emphasized the need to keep in mind whether this phenomenon is specifically related to the pathochemistry of schizophrenia (7). Radhakrishnan et al (4) showed that thyroid dysfunction was present in patients with schizophrenia spectrum disorders.

We found no association between thyroid hormones and clinical subtypes of schizophrenia. Similarly, another study reported that there was no statistically significant difference between thyroid hormone levels and clinical subtypes of schizophrenia (8). The PANSS is an instrument used for assessing the severity of schizophrenia symptoms (12). Positive symptoms reflect an excess or distortion of the individual's normal functioning, while negative symptoms are characterized by the absence of normal behaviour (13). We found a very mild negative correlation between PANSS-N and levels of TSH. There was no correlation between thyroid hormones and PANSS. The positive symptoms of schizophrenia are more related to the dopaminergic-based system, and the serotonergic system is more associated with negative symptoms (14).

Deficient serotonin function has been thought to cause some negative symptoms in schizophrenic patients (3). In a study, TSH levels were not significantly correlated with the PANSS total scores or the duration of disease in early psychosis patients. In contrast to our findings, the level of TSH showed a positive correlation with the negative symptoms scale of the PANSS (15). Rao et al (16) observed significantly increased TSH levels in schizophrenia patients with positive, negative and cognitive symptoms when compared with control subjects. Also, the level of TSH was found to be higher in chronic patients as compared with acute patients. When the TSH levels were compared in schizophrenia patients with positive and negative symptoms, the decrease in patients with positive symptoms was found more significant.

The most important limitation of this study was that we could not take patients who were not taking any medication and also we could not analyse the dosage of the medications. The present findings suggest that neuroleptics may be responsible for hypothyroidism. Schizophrenic patients show common thyroid disorders both in the acute and chronic periods. So, this issue will continue to be the focus of attention in schzophrenic patients. Although neuroendocrine differences between the positive and negative symptoms of schizophrenia have been reported, further studies are required for detecting possible association between the severity of symptoms and 
thyroid hormones.

\section{REFERENCES}

1. Akiibinu MO, Ogundahunsi OA, Ogunyemi EO. Inter-relationship of plasma markers of oxidative stress and thyroid hormones in schizophrenics. BMC Res Notes 2012; 5: 169.

2. Bunevicius R, Prange AJ Jr. Thyroid disease and mental disorders: cause and effect or only comorbidity? Curr Opin Psychiatry 2010; 23: 363-8.

3. Santos NC, Costa P, Ruano D, Macedo A, Soares MJ, Valente J et al. Revisiting thyroid hormones in schizophrenia. J Thyroid Res 2012; 2012: 569147.

4. Radhakrishnan R, Calvin S, Singh JK, Thomas B, Srinivasan K. Thyroid dysfunction in major psychiatric disorders in a hospital based sample. Indian J Med Res 2013; 138: 888-93.

5. Joffe RT, Marriott M. Thyroid hormone levels and recurrence of major depression. Am J Psychiatry 2000; 157: 1689-91.

6. Kelly DL, Conley RR. Thyroid function in treatment-resistant schizophrenia patients treated with quetiapine, risperidone, or fluphenazine. J Clin Psychiatry 2005; 66: 80-4.

7. Baumgartner A, Pietzcker A, Gaebel W. The hypothalamic-pituitary-thyroid axis in patients with schizophrenia. Schizophr Res 2000; 44: 233-43.

8. Cheng M, Wen S, Zhong Z. Analysis of thyroid hormone changes and related factors in first-episode schizophrenia patiens. Chin J Health Lab Tech; 2012.

9. Rao ML, Strebel B, Halaris A, Gross G, Braunig P, Huber G et al. Circadian rhythm of vital signs, norepinephrine, epinephrine, thyroid hor- mones, and cortisol in schizophrenia. Psychiatry Res 1995; 57: 21-39.

10. Roca RP, Blackman MR, Ackerley MB, Harman SM, Gregerman RI. Thyroid hormone elevations during acute psychiatric illness: relationship to severity and distinction from hyperthyroidism. Endocr Res 1990; 16: 415-47.

11. Takahashi T, Zhou SY, Nakamura K, Tanino R, Furuichi A, Kido M et al. Longitudinal volume changes of the pituitary gland in patients with schizotypal disorder and first-episode schizophrenia. Prog Neuropsychopharmacol Biol Psychiatry 2011; 35: 177-83.

12. Edgar CJ, Blaettler T, Bugarski-Kirola D, Le Scouiller S, Garibaldi GM, Marder SR. Reliability, validity and ability to detect change of the PANSS negative symptom factor score in outpatients with schizophrenia on select antipsychotics and with prominent negative or disorganized thought symptoms. Psychiatry Res 2014; 218: 219-24.

13. Odinka PC, Ndukuba AC, Muomah RC, Oche M, Osika MU, Bakare $\mathrm{MO}$ et al. Positive and negative symptoms of schizophrenia as correlates of help-seeking behaviour and the duration of untreated psychosis in south-east Nigeria. South Afr J Psychiatry 2014; 20: 166-71.

14. Bilici M, Kavakcı O, Cetin I, Karahan C, Bekaroğlu M, Uluutku N. Hypothalamo-pituitary-thyroid axis functions in positive and negative schizophrenia compared to healthy controls. Bull Clin Psychopharmacol 2000; 10: 81-9.

15. Shrivastava A. Neuroendocrines in first episode schizophrenia. Selected Works of Amresh Shrivastava; 2014.

16. Rao YR, Pongiya UD, Khan MR, Chinnasamy P. Psychopathological endocrine imbalance in schizophrenia patients with positive, negative and cognitive symptoms. World J Pharm Pharmaceut Sci 2014; 3: $1043-52$. 